\title{
Why do maintenance and repair matter? ${ }^{1}$
}

\author{
Jérôme Denis and David Pontille \\ Centre de Sociologie de l'Innovation \\ I3 (CNRS UMR 9217) - Mines ParisTech - PSL University \\ 60 Boulevard Saint Michel - 75272 Paris cedex 06 \\ jerome.denis@mines-paristech.fr \\ david.pontille@mines-paristech.fr
}

in: Anders Blok, Ignacio Farías \& Celia Roberts (eds.), 2020, The Routledge Companion to Actor-
Network Theory. New York: Routledge, p. 283-293.

\section{The rise of maintenance and repair studies}

In 'Power, technology and the phenomenology of conventions: on being allergic to onions,' Star (1991) recalls how science and technology studies helped reconsider the question of power in social science. One of the main outcomes of STS, she states, is that they demonstrate that both science and technology are what Latour (1987) called 'politics by other means.' Identifying the contributions of different streams of research and the more or less passionate disputes that arose between them, Star specifically highlights the weaknesses and the gaps of ANT-oriented accounts. Most of those, she claims, following Haraway (1991) and Fujimura (1991), are a matter of standpoints. While Callon, Law and Latour, among others, aim to open the black boxes of facts and artefacts in order to describe hitherto invisible processes, they stand - and remain - on the side of the 'winners': Those whose translations and intéressements are successful, and those who delegate and discipline. ANT scholars don't devote many words, if any at all, to those who are translated, disciplined and delegated to. This is highly problematic, Star argues: Not only are the experiences of the latter worth examination in order to study 'politics by other means,' but the place of these 'losers' and their own invisible work are crucial to the very stability of the networks in which they participate. To

\footnotetext{
1 In the published version of this chapter, the author-in-the-text is David J. Denis. However, the author-in-theflesh, just as the one who appears on this open access version, is twofold: Jérôme Denis and David Pontille. Since the end of the 1990s, we have used the attachment of our two civil names as a way 'to diffract' our own authorship, following Haraway (1996), and to disrupt the emphasis of single individuals performed by most of research assessment frameworks. As the editors of the ANT Companion were concerned with two different chapters bearing the same name(s), we created a fictional author as a way to pursue the diffraction process. Such a gesture is perfectly in line with the semiotic foundation of anthropology of writing and ANT (see the second footnote in Latour, 1988), which both insisted on the generative process of writing practices that bring new entities to existence and participate in their maintenance. The different fieldworks mobilised in this chapter come from Denis and Pontille's common investigations. See also Jérôme D. Pontille's chapter in the same volume.
} 
illustrate her point, Star returns to Latour's famous 'sociology of a door-closer' (Latour, 1988) and dwells on one of his sentences:

As a technologist, I could claim that, provided you put aside maintenance and the few sectors of population that are discriminated against, the groom does it job well, closing the door behind you constantly, firmly and slowly. (Latour, 1988, p. 302)

To that hypothetical statement, Star retorts that:

There is no analytic reason to put aside maintenance and the few sectors of population that are discriminated against, in fact, every reason not to. (Star, 1991, p. 42, our highlights)

During the two decades that followed the publication of Star's paper, numerous works in STS have enriched the critique of ANT, thanks notably to feminist scholars. ANT 'itself' has evolved, and its most well-known contributors have taken some of these recriminations into consideration (Latour, 2005; Law \& Hassard, 1999). Yet, most of these critiques and adjustments have echoed only the second part of Star's statement. It's first half has long been ignored, with maintenance remaining an obscure, largely unexplored domain. Recently, however, a body of academic work on maintenance and repair has been rapidly growing, providing important contributions to science and technology studies by shifting the attention from the processes of 'form-giving' to those of 'form-keeping' in Ingold's terms (Ingold, 2013).

Even though Akrich (1993), Orr (1996) and de Laet and Mol (2000) have paved the way, it is undoubtedly the contributions of Henke (2000) and Graham and Thrift (2007) that set the agenda 2 of what we can call today 'maintenance and repair studies.' In these seminal papers, the three authors shape the problematisation of maintenance and repair, building on Goffman's work on 'backstage' activities and the vulnerability of social interaction (Goffman, 1959), and on the ethnomethodological analysis of 'repair' in conversation (Schegloff, Jefferson \& Sacks, 1977). Their demonstration is straightforward: If social order is constantly maintained by generally unnoticed gestures during interaction, we should also investigate the operations that daily shape and preserve material order. Whether accomplished by dedicated workers or lay persons, made on huge technological systems or small objects, these operations, which are 'the main means by which the constant decay of the world is held off' (Graham \& Thrift, 2007, p. 1), are indeed countless. Their close and careful examination should, therefore, considerably help refine and strengthen our understanding of the role of objects and technology in the very constitution and continuation of modern societies. This is what Edgerton, another pioneering scholar on the subject, please for in his book The Shock of the Old, a chapter of which is entirely devoted to maintenance. Maintenance and repair, he states, though particularly difficult to grasp, are essential dimensions of the global history of technology (Edgerton, 2006, p. 75102).

Since these early appeals, maintenance and repair have been of growing interest in various areas of research, and more and more scholars have brought to light an incredible variety of 
hitherto neglected objects and practices. In the last years, studies have documented maintenance and repair activities in ICTs (Cállen \& Sánchez Criado, 2015; Houston \& Jackson, 2016; Jackson, Pompe \& Krieshok, 2012; Rosner \& Ames, 2014), Arts (Domínguez Rubio, 2016), large infrastructures (Barnes, 2017; Ureta, 2014), software and information systems (Cohn, 2016; Fidler and Russel, 2018), urban settings (Denis \& Pontille, 2014, 2018; Strebel, 2011), legacy buildings and heritage sites (Edensor, 2011; Jones \& Yarrow, 2013), domestic consumption (Gregson, Metcalfe \& Crewe, 2009; Rosner, 2013) and even corpse preservation (Yurchak, 2015). In the following sections, we propose to give hints on these emerging maintenance and repair studies by articulating, beyond their variety, two of their main contributions. First, l'll show that maintenance and repair studies help reconsider an old legacy of ANT: The opposition between breakdown (crisis, controversy) and routine (taken-forgrantedness). Second, we will suggest that these studies renew the way matter (or 'materiality') is generally treated in ANT accounts, namely as 'that which resists. ${ }^{3}$

\section{Before breakdown, beyond closure}

Most researchers investigating maintenance and repair are wary of what Edgerton calls 'innovation-centric accounts' (Edgerton, 2006, p. xi). They aim instead to produce more balanced depictions through the (re)discovery of the people, workers and users who participate in the daily life of technologies, long after their invention. Maintenance and repair studies thus append a constantly expanding gallery of portraits to the figure of the lonely innovator. Withdrawing from the innovation-centric approach by exploring maintenance and repair activities also helps to widen the understanding of objects themselves. Things that are maintained and repaired are far from what Jackson calls the 'bright and shiny tools' (Jackson, 2014 , p. 227) that innovation-centric accounts exclusively focus on, and that studies of technology generally stage. As Domìnguez Rubio (2016) reminds us, the brand-new, perfectly shaped and fully functional objects some scholars seem to have in mind when they insist on material agency are sparse in our daily lives. We rarely deal with pristine artefacts. Rather, we use and live surrounded by countless things that age more or less dramatically. Actually, technologies usually live a long life, even the most complex ones: Ships, airplanes, cars (Edgerton, 2006), urban infrastructures (Graham, 2010), software (Cohn, 2016)... Yet, longlasting objects are neglected in innovation-centric accounts, and in most STS reflections. So are the manifold operations, from routine maintenance to exceptional repair, that take part in the durability of these objects. Maintenance and repair studies aim at bringing this unseen territory to the fore.

In doing so, these studies also encourage reconsideration of ANT's traditional approach to what appears to be the opposite side of brightness and sheen: breakdown. Since ANT's inception, breakdown has played a crucial role in what we can call its Heideggarian posture. This posture distinguishes two conditions for technologies. The first one is characterised by ordinariness and describes a technology 'ready at hand' in the sense of Heidegger (Verbeek, 2006), that is taken for granted. Used without being questioned, artefacts here function as

3 Brand's book How building learn (1994) should also be mentioned. Although not academic, it has inspired early research on maintenance. 
'black boxes': Stable objects whose composition is mostly unknown. It is this very mundaneness that gives power to technologies, most ANT accounts argue. Since nobody knows what these artefacts are made of, the decisions and the assumptions that are inscribed in them become naturalised. Automation, routine and mundane uses are the 'other means' of politics here. But such a peaceful state is problematic for scholars who, under such conditions, cannot grasp the political and moral dimensions of technologies. In order to reveal these dimensions, ANT and most STS scholars claim, one has to find the moments when technologies become 'present at hand,' that is debated, discussed and problematised anew. Accidents, controversies and breaks are typical of these moments: They are occasions of breakdown that shatter black boxes, interrupt any taken-for-grantedness and bring numerous hitherto invisible components to light. Breakdown, in contrast to routine, brings the sociotechnical depth of technologies into light.

To call this binary reading of technology into question is one of the main contributions of maintenance and repair studies. Indeed, studying maintenance and repair practices precisely consists in paying attention to all the overlooked situations that take place in the interstices of routine and breakdown, situations in which technologies are never completely functional and never completely broken:

It is in this space between breakdown and restoration of the practical equilibrium-between the visible (that is, 'broken') tool and the concealed tool-that repair and maintenance make its bid for significance. (Graham \& Thrift, 2007, p. 3)

This has important consequences, for instance, for the way in which infrastructures can be questioned and analysed beyond the rhetoric of great catastrophes and collapses. The master narratives that focus attention towards the threats of disasters actually obscure the way infrastructures work on a daily basis. Yet, their mundane mode of existence is less characterised by the risks of technological apocalypse than by 'a vast and hidden economy of repair and maintenance ... continually at work' (Graham, 2010, p. 10).

Investigating things in such intermediary states inherently leads us to reconsider another early ANT bedrock: the widespread metaphor of closure. Even at rest, artefacts are not as sealed and as stable as they may appear, maintenance and repair studies show. The ability for technologies to remain the same and to be taken for granted by most of their users requires a constant work that such terms as 'black box' or 'immutable mobiles' seriously understate.

Studying dwelling maintenance, for example, Strebel (2011) coins the notion of 'living building' to highlight the mundane life of edifices, daily punctuated with repair and maintenance operations:

The living building is another kind of architectural drama, one that is performed in and through the successive scenes of interruptions, troubles and disturbances that concierges continually encounter and the ways they solve these problems in order to keep the building going. ( $p$. 259) 
The interruptions and troubles Strebel describes remind us that, for some people and in some situations, even the apparently most stable artefacts cannot be totally taken for granted. Maintenance work engages certain people in very specific relationships with objects that hinder complete closure and opacity.

Exploring maintenance and repair also leads us to discover forms of troubles and malfunctioning that are not always, and not by everybody, considered as breakdowns. This is particularly visible in situations where specialised maintenance workers take care of artefacts that users are supposed to enjoy as if they were always available and functioning. The takenfor-grantedness these users can rely on is the result of the ceaseless attention and intervention of maintenance workers. The mission of the latter is to detect breaches and flaws before any breakdown can be experienced by the former (Denis \& Pontille, 2015). Mentioning the different relationships a railroad engineer and a passenger have with rails, Star explains that 'one person's infrastructure is another's topic, or difficulty' (Star, 1999, p. 380). In a similar manner, maintenance and repair studies show that, in many situations, one person's breakdown, or 'repairable' in ethnomethodogy's terms (Schegloff, Jefferson \& Sacks, 1977), is another's mundane functioning.

More generally, these studies also show that breakdown is not necessarily a clearly identifiable event. Rosner and Ames' comparative research on the 'One Laptop Per Child' operation in Paraguay and the Fixit Community in California foregrounds, for instance, the relationality of breakage, which is not a universal, univocal thing that happens to objects. Rosner and Ames (2014) demonstrate that both in Paraguay and in California, 'definitions of breakdown lay on a continuum' (p. 328). Similarly, Cállen and Sánchez Criado (2015) insist on the repeated trials and tests that allow the various menders they observed to gauge the flaws and fragilities of objects that are not clearly broken:

Despite the fact that vulnerability is in many practical situations easy to identify - such as when a clear breakage happens while using something, after an accident or as a result of a disaster - it usually emerges out as part of an ongoing process of sensing and practical manipulation, hardly ever recognised at first glance. (p. 22)

These accounts of neither fully functioning nor definitely broken technologies resonate with de Laet and Mol's description of the Zimbabwe Bush Pump, the breakdown of which, they show, is nothing but an 'intermediate stage' (de Laet \& Mol, 2000, p. 240). In fact, in numerous situations, the endurance of objects is negotiated (Cohn, 2019; Rosner \& Ames, 2014), and overly limited definitions of breakdown are contested.

What is at stake, therefore, is not only the reconsideration of breakdown, but also of stability and order itself, as relational phenomena that draw on and are inscribed in specific repair and maintenance activities. 


\section{Rethinking matter: fragility and material ecology}

Another important contribution of maintenance and repair studies consists in providing a particularly distinctive look at objects and their role in modern societies. Following ANT, maintenance and repair scholars refuse to reduce artefacts to signs or receptacles of external social forces (Latour, 1996). Yet, their extensive forays into the material dimensions of the world lead to unprecedented depictions, and prompt a decentring of the investigation of matter and materiality beyond the sole figure of immutability. Inspired by Mol (2008) and Puig de la Bellacasa (2011), several works have notably highlighted the relationships between maintenance, repair and care (Denis \& Pontille, 2015; Houston \& Jackson, 2016; Jackson, 2014). As care, maintenance and repair practices indeed take decay and vulnerability as a starting point. Fragility is here the primary - 'normal' - property of matter. Everything has, in a way or another, to be taken care of.

Such a stance markedly contrasts with how objects' agency is problematised in most ANTinspired works, which have typically focused on solidity, resistance and permanence. If artefacts' abilities to shape our world are to be questioned, maintenance and repair studies claim, they also have to be investigated in the most mundane situations, including those in which these abilities appear uncertain, even failing. In other terms, maintenance and repair bring to light an overlooked side of objects that scholars interested in understanding material agency should not ignore.

During our own investigation on subway signs design in Paris (Denis \& Pontille, 2014; 2015), we experienced such a revelation. We started our research following the lead of standardisation, eager to understand the genesis of the Parisian wayfinding system. At first, in an early ANT fashion, we recognised an ordering process, in which a new set of omnipresent and standardised signs had been given a crucial role. Yet, once we entered the maintenance department and encountered the maintenance workers, we discovered a completely different aspect of the mode of existence of these seemingly immutable and immobile signs, and was forced to seriously reconsider the way we had analysed the whole ordering process.

Shadowing several maintenance runs, we progressively understood that the standardisation, stability and permanence of the set of signs actually drew on a constant care, a daily attention to the numerous mutations the signboards were subject to (wear, moisture, rust, strokes, thefts...). The signs were thus materially fragile and their strength was enacted by a daily maintenance work.

In his study of conservation of the Saint Anne Church in Manchester, Edensor (2011) investigated the 'materiality' of the stone, a solid entity par excellence that one might consider as the most immutable thing to be. Edensor explains that in the eyes and hands of the workers who strive for historical authenticity, Saint Anne's stone presents, on the contrary, unstable properties that vary over time. Far from being inert and impervious to its environment, the stone is subject to numerous deteriorations (i.e. discoloration, crumbling, cracking...) that challenge not only the aesthetic characteristics of the legacy building, but its very permanence.

Besides putting fragility to the fore and thus widening the understanding of material agency, maintenance and repair studies also directly echo Ingold's call for exploring the material heterogeneity of objects, technologies and infrastructures. Ingold writes, 
it is as though our material involvement begins only when the stucco has already hardened on the house front or the ink already dried on the page. We see the building and not the plaster of its walls, the words and not the ink with which they were written. In reality, of course, the materials are still there and continue to mingle and react as they have always done, forever threatening the things they comprise with dissolution or even 'dematerialization'. (Ingold, 2007, p. 9-10)

If meticulously observed, activities such as mending, restoring, up-keeping, fixing or preserving offer manifold occasions to fathom the material ecology that is hidden when objects are apprehended as crystallised artefacts. These activities precisely deal with the crumbling plaster, the ink and more generally the way materials interact long after the processes of 'formgiving' (Ingold, 2013). Repair and maintenance operations bring to light the material 'intraactions,' a term that Barad (2003) uses to characterise the kinds of material transformations that do not imply the encounter of previously recognisable discrete components.

The workers in charge of preserving Saint Anne's Church (Edensor, 2011) do not consider the building as a unified and stabilised entity. On the contrary, they deal with it as an unsettled assemblage of partly unknown elements, constantly subject to external and internal disruptions. Materials have been added to the structure of the church over time (iron staples, mortar...), and their behaviours have important consequences on the building's life. The quality of air, which has been changing over the years, is also critical to the church assemblage, as are 'birds, bats, rodents, insects, bacteria, plants, fungus, lichen and moss' (Edensor, 2011, p. 242). Preserving a heritage building requires a considerable amount of work which largely consists in exploring this particularly complex and uncertain material ecology and tackling its challenges.

It is important to note, though, that maintenance and repair studies do not fully endorse Ingold's normative stance: There is no such essentialist expressions as 'in reality' in their accounts. What maintenance and repair studies investigate are the situated enactments of the material properties of objects, through specific instruments, theories, gestures, skills, etc. Far from being the result of an academic interpretative work, the recognition that 'the artefact is not a discrete entity but a material form bound into continual cycles of articulation and disarticulation' (DeSilvey, 2006, p. 335) is always staged as a grounded and partial outcome of repair and maintenance practices themselves.

Notably, this means that the components of the material ecology are anything but a starting point in repair and maintenance activities. There are no such things as an exhaustive list of relevant material properties or a stabilised body of knowledge that would provide a strict framework for handling the things that are to be taken care of. Repair and maintenance practices are exploratory and imply a great amount of improvisation (Henke, 2000; Orr, 1996). This is telling in the contrasted cases of informal maintenance practices studied by Callén and Sánchez Criado (2015). The migrant waste pickers and the 'hackers' in collective repair workshops both engage in exploration processes. They progressively identify material properties and artefact vulnerability 'through attentive and careful 'tests' on matter' (p. 22) ranging from situated sensing and manipulating to informal experiments. 
These material enactments obviously involve workers' bodies. Making 'matter speak' (Sanne, 2010) and 'listening' to it are embodied processes. Dant (2008; 2010) has regularly emphasised the importance of perception in maintenance and repair. He showed that mechanics who repair cars engage in a continuous interaction with matter, as they try to appraise the composition and condition of objects, not only touching, hearing and smelling (and sometimes tasting) them, but also configuring a convenient 'manipulatory zone' through their displacements (Dant, 2005). As one may imagine, such embodied explorations are far from always being gratifying and safe, and maintenance and repair activities should not be over-romanticised. Besides dealing with dirt (Dant \& Bowles, 2003; Shaw, 2014), disassembling objects and exploring matter sometimes put workers' health at risk, especially when their activities take place in countries with fewer safety regulations (Gregson, 2011).

It is worth adding though that the interest in perception and embodied practices in maintenance and repair studies does not aim to revive any body/matter dualism. Neither bodies nor knowledge are isolated from an alleged external environment in this work. In his pioneering paper, Henke, for instance, describes the body of repair workers as a 'networked body' to emphasise the material and cognitive interdependencies of repair work:

... in fact, it may be more appropriate to say that a given worker's body is 'networked' through performances of skilled repair. This does not mean, of course, that the body does not learn, but rather that the interaction of body and setting is the crucial relationship to understand repair. (Henke, 2000, p. 63-64)

Hence, human bodies are fully part of the material ecology that maintenance and repair activities assemble in situ.

Several works in maintenance and repair studies also insist on the organisational and geographical distribution of activities (Edensor, 2011; Jackson, Pompe \& Krieshok, 2012; Domínguez Rubio, 2014). Repairing mobile phones in the workshops of downtown Kampala, for instance, is not as local an activity as it may seem. It is framed by different authorisation regimes that shape specific dependencies with manufacturers and network providers and involve:

a complex global and local flows that sustain repair work, ranging from forms of local collaboration (though also competition) that connect technicians (...) to the wider distributions of knowledge, expertise and material resources to be found in the tools and online resources that local repair workers regularly draw on in tackling the breakdowns they confront. (Houston \& Jackson, 2016, p. 8)

In addition to the sometimes chaotic material ecology of workshops, thus, 'an ecology of tool developers, who sometimes hack each other's devices in the pursuit of unlocking algorithms' (Houston \& Jackson, 2016, p. 9), is at play. The extended view Houston and Jackson provide on mobile phone repair greatly illustrates how maintenance and repair studies help explore the multiple 'entangled agencies' (Edensor, 2011) that characterise the life of 
objects, way beyond the divide between alleged 'human' and 'non-human' agencies and the obsession around sturdiness and immutability.

\section{Conclusions}

Let us gather the contributions of maintenance and repair studies we underlined here with a quick summary of a case Dominguez Rubio has been investigating during his research on contemporary art conservation (Domínguez Rubio, 2014). Certain 'unruly' artworks, Domìnguez Rubio explains, can be particularly challenging for Museums in their

ongoing effort to control the unrelenting process of physical degradation that threatens to undermine the specific relationship between material form and intention that defines artworks as meaningful and valuable objects. (p. 620)

This is the case of Nam June Paik's 'Untitled,' in the Museum of Modern Art (MoMA) in New York. The original technologies this installation was based on (U-Matic desks, CRT monitors, analogic cameras...) progressively became obsolete and its conservation involved the replacement of several of its components. As long as he lived, the artist supervised and validated all of these delicate 'updates' but when he died, the MoMa faced uncertainties and dilemmas. How could the team of curators and conservators decide to replace a piece without endangering the authenticity of the artwork? How far should the maintenance of the oldest technologies go? What Domingez Rubio shows is that the discussions and negotiations deployed to tackle these issues not only have consequences on the material and symbolic composition of the artwork itself, but also transform the organisation of the museum, modifying the hierarchies between curators and conservators and expanding this traditional landscape to encompass new actors (including computer scientists and audiovisual experts). From the standpoint of its continuous preservation, Nam June Paik's 'Untitled' thus appears as a vulnerable artefact never completely broken, but never opaque nor taken for granted for its various caretakers, who constantly explore the uncertain material ecology in which it takes part in order to enact, again and again, its stability and authenticity.

The body of work that we have assembled here under the probably-too-fashionable expression of 'maintenance and repair studies' is, of course, heterogeneous and does not offer a coherent set of empirical results and theoretical developments. Yet, it does account for a certain sensibility, an 'ethos of care' (Puig de la Bellacasa, 2011) that directly echoes Star's call for taking the neglected entities of sociotechnical assemblages into account (Star, 1991). Moreover, the issues these 'studies' raise go way further the questions we isolated in this chapter in order to underline their contributions to the so-called 'post-ANT' landscape. What should be kept in mind is that they raise the curtain on what appears to be a vast continent of people, objects, sites and practices that, although familiar and mostly accessible, remained unnoticed and unexplored for decades. Considering the variety of objects and situations these first works scrutinise and the richness of their analysis, there are a few doubts that we are just at the beginning of a long-lasting trend that will lead to more exciting discoveries. 
Besides this empirical variety, it is also important to recognise the theoretical potential of maintenance and repair studies, each of their explorations offering an occasion to document original ways of enacting order, identity and authenticity, but also inviting us to denaturalise the relationship between maintenance and order. Whilst one may think that maintaining objects or infrastructures always amounts to bringing things back to order, we saw here that things are not so simple. First, studying maintenance and repair directs attention to the relationality of order (if an order is repaired or maintained, which one is it, from which standpoint?). Second, certain forms of maintenance have less to do with order than with precariousness and the life that emerges in the interstices (or the ruins) of innovation and even capitalism (Tsing, 2015).

Maintenance and repair studies also bring ways to unfold and discover power relations from the starting point of the various object ontologies that are enacted in distinct regimes of maintenance, from generalised care to organised non-reparability (Denis \& Pontille, 2017). They thus pursue the ontological inquiry that ANT instigated in social sciences, by collecting and describing hitherto unexplored situations in which the question 'what is (and remain) an object?' is practically addressed.

\section{References}

Akrich, M. 1993. Essay of Technosociology: A Gasogene in Costa Rica. In Lemonier, P. (Ed.), Technological Choices. Transformation in Material Cultures since the Neolithic. London, Routledge, p. 289-337.

Barad, K. 2003. Posthumanist Performativity: Toward an Understanding of How Matter Comes to Matter. Signs: Journal of Women in Culture and Society, 28(3), p. 801-831.

Barnes, J.E. 2017. States of Maintenance: Power, Politics, and Egypts Irrigation Infrastructure. Environment and Planning D: Society and Space, 35(1), p. 146-164.

Brand, S. 1994. How Buildings Learn: What Happens after They're Built. New York, Viking Penguin.

Cállen, B. \& Sánchez Criado, T. 2015. Vulnerability Tests. Matter of 'Care for Matte' in E-waste Practices. Tecnoscienza, 6(2), p. 17-40.

Cohn, M.L. 2019. Keeping Software Present: Software as a Timely Object for Digital STS. In Vertansi, J. \& Ribes, D. (Eds.), Digital STS: A Fieldguide and Handbook. Princeton, Princeton University Press, p. 423-446

Dant, T. 2005. Materiality and Society. New York, Open University Press.

Dant, T. 2008. The 'Pragmatic' of Material Interaction. Journal of Consumer Culture, 8(1), p. 1133.

Dant, T. 2010. The Work of Repair: Gesture, Emotion and Sensual Knowledge. Sociological Research Online, 15(3), p. 1-22.

Dant, T. \& Bowles, D. 2003. Dealing with Dirt: Servicing and Repairing Cars. Sociological Research Online, 8(2), p. 1-17.

de Laet, M., \& Mol, A. 2000. The Zimbabwe Bush Pump: Mechanics of a Fluid Technology. Social Studies of Science, 30(2), p. 225-263. 
Denis, J. \& Pontille, D., 2014. Maintenance Work and the Performativity of Urban Inscriptions: the Case of Paris Subway Signs. Environment and Planning D: Society and Space, 32(3), p. 404-416.

Denis, J. \& Pontille, D., 2015. Material Ordering and the Care of Things. Science, Technology, \& Human Values, 40(3), p. 338-367.

Denis, J. \& Pontille, D. 2017. Beyond Breakdown: Exploring Regimes of Maintenance. continent., 6(1), p. 13-17.

Denis, J. \& Pontille, D. 2018. The Multiple Walls of Graffiti Removal. Maintenance and Urban Assemblage in Paris. In A. M. Brighenti \& M. Kärrholm (Eds.), Urban Walls. Political and Cultural Meanings of Vertical Structures and Surfaces. London,Routledge, p. 215-235.

DeSilvey, C. 2006. Observed Decay: Telling Stories with Mutable Things. Journal of Material Culture, 11(3), p. 318-338.

Domínguez Rubio, F. 2014. Preserving the Unpreservable: Docile and Unruly Objects at MoMA. Theory and Society, 43(6), p. 617-645.

Domínguez Rubio, F. 2016. On the Discrepancy between Objects and Things. Journal of Material Culture, 21(1), p. 59-86.

Edensor, T. 2011. Entangled Agencies, Material Networks and Repair in a Building Assemblage: the Mutable Stone of St Ann's Church, Manchester. Transactions of the Institute of British Geographers, 36(2), p. 238-252.

Edgerton, D. 2006. The Shock of the Old: Technology and Global History since 1900. London, Profile books.

Fidler, B.R. \& Russel, A. 2018. Financial and Administrative Infrastructure for the Early Internet: Network Maintenance at the Defense Information Systems Agency, Technology and Culture, 59(4), p. 899-924.

Fujimura, J.H. 1991. On Methods, Ontologies and Representation in the Social Sciences: Where Do We Stand? In David R. Maines (Ed.) Social Organization and Social Process: Essays in Honor of Anselm Strauss. Hawthorne, Aldine de Gruyter, p. 207-248.

Goffman, E. 1959. The Presentation of Self in Everyday Life. New York, Anchor.

Graham, S. 2010. When Infrastructures Fail. In S. Graham (Ed.) Disrupted Cities. New York, Routledge, p. 1-26.

Graham, S. \& Thrift, N. 2007. Out of Order: Understanding Repair and Maintenance. Theory, Culture \& Society, 24(3), p. 1-25.

Gregson, N. 2011. Performativity, Corporeality and the Politics of Ship Disposal. Journal of Cultural Economy, 4(2), p. 137-156.

Gregson, N., Metcalfe, A. \& Crewe, L. 2009. Practices of Object Maintenance and Repair: How Consumers Attend to Consumer Objects within the Home. Journal of Consumer Culture, 9(2), p. 248-272.

Haraway, D.J. 1991. Simians, Cyborgs, and Women: The Reinvention of Nature. New York, Routledge.

Haraway, D.J. 1996. Modest_Witness@Second_Millennium.

FemaleMan(C_Meets_OncoMouse ${ }^{\mathrm{TM}}$. Feminism and Technoscience. New York, Routledge.

Henke, C.R., 2000. The Mechanics of Workplace Order: Toward a Sociology of Repair. Berkeley Journal of Sociology, 44, p. 55-81. 
Houston, L. \& Jackson, S.J., 2016. Caring for the Next Billion Mobile Handsets: Opening Proprietary Closures through the Work of Repair. Proceedings of the Eighth International Conference on Information and Communication Technologies and Development. p.10.

Ingold, T. 2007. Materials Against Materiality. Archaeological Dialogues, 14(01), p. 1-16. Ingold, T. 2013. Making: Anthropology, Archaeology, Art and Architecture. London, Routledge. Jackson, S.J. 2014. Rethinking Repair. In Gillespie, T., Boczkowski, P.J. \& Foot, K.A. (Eds.), Media Technologies - Essays on Communication, Materiality, and Society. Cambridge, MA MIT Press, p. 221-240.

Jackson, S.J., Pompe, A. \& Krieshok, G., 2012. Repair Worlds: Maintenance, Repair, and ICT for Development in Rural Namibia. CSCW'12. Seattle.

Jones, S. \& Yarrow, T. 2013. Crafting Authenticity: An Ethnography of Conservation Practice. Journal of Material Culture, 18(1), p. 3-26.

Latour, B. 1987. Science in Action. How to Follow Scientists and Engineers Through Society. Harvard, Harvard University Press.

Latour, B. 1988. Mixing Humans and Non-Humans Together: The Sociology of a Door-Closer. Social Problems, 35, p. 298-310.

Latour, B. 1996. On Interobjectivity. Mind, Culture, and Activity, 3(4), p. 246-269.

Latour, B. 2005. Reassembling the Social: An Introduction to Actor-Network-Theory. Oxford, Oxford University Press.

Law, J. \& Hassard, J. 1999. Actor Network Theory and After. Oxford, Wiley-Blackwell.

Mol, A. 2008. The Logic of Care: Health and the Problem of Patient Choice. New York, Routledge.

Orr, J.E. 1996. Talking About Machines: An Ethnography of a Modern Job. New York, Cornell University Press.

Puig de la Bellacasa, M., 2011. Matters of Care in Technoscience: Assembling Neglected Things. Social Studies of Science, 41(1), p. 85-106.

Rosner, D.K., 2013. Making Citizens, Reassembling Devices: On Gender and the Development of Contemporary Public Sites of Repair in Northern California. Public Culture, 26(1 72), p. 5177.

Rosner, D.K. \& Ames, M., 2014. Designing for Repair?: Infrastructures and Materialities of Breakdown. Proceedings of the 17th ACM conference on Computer Supported Cooperative Work \& Social Computing. p. 319-331.

Sanne, J.M. 2010. Making Matters Speak in Railway Maintenance. In M. Büscher, D. Goodwin \& J. Mesman (Eds.) Ethnographies of Diagnostic Work: Dimensions of Transformative Practice. Houndmills, Palgrave Macmillan, p. 54-72.

Schegloff, E.A., Jefferson, G. \& Sacks, H., 1977. The Preference for Self-Correction in the Organization of Repair in Conversation. Language, 53(2), p. 361-382.

Shaw, R. 2014. Cleaning up the Streets: Newcastle-upon-Tynes Night-Time Neighbourhood Services Team. In Graham, S. \& McFarlane, C. (Eds.), Infrastructural Lives: Urban Infrastructure in Contexte. London, Routledge, p. 174-196. 
Star, S.L. 1991. Power, Technology and the Phenomenology of Conventions: on Being Allergic to Onions. In Law J. (Ed.), A Sociology of Monsters? Essays on Power, Technology and Domination. London/New York, Routledge, p. 26-56.

Star, S.L., 1999. The Ethnography of Infrastructure. American Behavioral Scientist, 43(3), p. 377-391.

Strebel, I., 2011. The Living Building: Towards a Geography of Maintenance Work. Social \& Cultural Geography, 12(3), p. 243-262.

Tsing, A.L. 2015. The Mushroom at the End of the World: on the Possibility of Life in Capitalist Ruins. Princeton, NJ, Princeton University Press.

Ureta, S. 2014. Normalizing Transantiago: On the Challenges (and Limits) of Repairing Infrastructures. Social Studies of Science, 44(3), p. 368-392.

Verbeek, P. 2006. Materializing Morality: Design Ethics and Technological Mediation. Science, Technology \& Human Values, 31(3), p. 361-380.

Yurchak, A. 2015. Bodies of Lenin: The Hidden Science of Communist Sovereignty. Representations, 129(1), p. 116-157. 